\title{
ATORES, CONFLITOS E POLÍTICAS PÚBLICAS PARA O CAMPO NO BRASIL CONTEMPORÂNEO
}

\author{
Leonilde Servolo de Medeiros*
}

\begin{abstract}
O artigo se volta para mudanças ocorridas nas quatro últimas décadas nas formas de organização dos trabalhadores do campo no Brasil, enfatizando disputas, convergências e impasses não só na relação entre os próprios atores em processo de constituição, mas também com os mecanismos institucionais e políticas públicas voltadas para o campo. Iniciamos com um breve histórico das mudanças que atingiram o meio rural e, na sequência, discutimos a dinâmica política da representação das categorias agricultura familiar, trabalho assalariado e, por fim, as faces contemporâneas da dinâmica da disputa fundiária. Procuramos mostrar como essas categorias se entrecruzam e como a preocupação classificatória tende a esconder a complexa rede de relações que articula diferentes segmentos do campo e suas organizações, cada vez menos perceptíveis como universos estanques. Finalmente, tratamos do crescente protagonismo do agronegócio e suas implicações para as disputas no campo e para a reconfiguração da questão agrária.

Palavras-chave: Representação política. Agricultura familiar. Assalariados. Conflitos fundiários. Agronegócio.
\end{abstract}

Nas quatro últimas décadas ocorreram significativas mudanças no meio rural brasileiro, reconfigurando disputas, atores e significados do que se convencionou chamar de questão agrária. Elas caminharam lado a lado com a construção de novas identidades, formas de nomeação dos trabalhadores rurais, demandas e formas convencionais de representação e participação política, com uma progressiva transformação nas instituições voltada para o desenho de políticas para a agropecuária e produção de novas configurações dos setores dominantes nas áreas rurais.

Para tanto, foram importantes tanto transformações legais, configuradas na Constituição de 1988, significativo marco da conquista de direitos por esses trabalhadores, quanto uma série de políticas governamentais, tais como assentamentos de demandantes de terra; políticas de apoio à agricultura familiar; regulamentações para demarcação de terras de povos indígenas

* Universidade Federal Rural do Rio de Janeiro. Programa de Pós-graduação de Ciências Sociais em Desenvolvimento, Agricultura e Sociedade.

Av. Presidente Vargas, 417, $8^{\circ}$ andar. Cep: 20071-003. Rio de Janeiro - Rio de Janeiro - Brasil.

leonildemedeiros@gmail.com

https://orcid.org/0000-0001-5030-8044 e comunidades tradicionais, entre outras. Para a compreensão desse complexo processo, é fundamental considerar as condições econômicas, sociais e políticas que levaram à emergência de novas categorias, identidades e demandas que reconfiguraram o campo da representação política não só dos trabalhadores do campo, mas também dos segmentos patronais. Elas se desenham num contexto em que se fortalece a discussão sobre o papel da moderna agricultura na economia, trazendo para o centro da disputa o significado do agronegócio e os rearranjos que sua consolidação e legitimação provocam no conjunto dos embates políticos que ultrapassam, e muito, os limites do agro.

Na última década, essas disputas se intensificaram e sinalizaram claramente um redesenho das políticas para o campo. Em especial de 2016 em diante, a partir dos governos Temer e Bolsonaro, verifica-se o progressivo desmantelamento da institucionalidade anteriormente criada e só aparentemente consolidada, trazendo à tona forças sociais e concepções de rural que pareciam estar superadas. Uma das primeiras medidas do governo Temer, não por acaso, foi a extinção do Ministério do 
Desenvolvimento Agrário (MDA), criado vinte anos antes, em 1996, no governo Fernando Henrique Cardoso. Suas funções foram transferidas ou para o Ministério da Agricultura ou para a Casa Civil da Presidência da República. ${ }^{1}$ Com isso, ganhou novas cores uma antiga disputa sobre as formas de inclusão dos chamados "agricultores familiares" numa política de estímulo à modernização e à lógica do mercado, reafirmando uma antiga tendência de secundarização dos seus segmentos mais frágeis. No caso da política de assentamentos rurais, ${ }^{2}$ que já vinha em declínio desde o segundo governo Lula, não só foi bloqueada, como passou-se a estimular a titulação definitiva dos lotes dos assentamentos existentes e, com isso, criar a possibilidade de devolver essas terras ao mercado mediante venda legalizada, num momento em que a terra cada vez mais se valoriza, internacionaliza e financeiriza. Acelerou-se a regularização fundiária e, portanto, a titulação de terras nas áreas com alta presença de posseiros, privilegiando os que controlam maiores parcelas. Foram também suspensas as demarcações de terras indígenas e de quilombolas. Essas iniciativas caminham lado a lado com a permissividade, denunciada na imprensa e por pesquisadores, em relação ao avanço do desmatamento e indicam a centralidade da questão fundiária nos anos recentes e uma forte tendência a ampliar a quantidade de terras sujeitas ao mercado em detrimento daquelas cujo uso foi స్․ garantido, pela própria Constituição Federal, N. aos que nela viviam desde há muito.

$\rightarrow 1$ O MDA foi criado num contexto de intensas disputas - fundiárias, com o crescimento das ocupações de terra e $\dot{2}$ de emergência da agricultura familiar como ator político.

; Além de ter sob sua órbita o Instituto Nacional de Coloni-

m. zação e Reforma Agrária (Incra), encarregado da política de

$>$ assentamentos rurais, também ficaram subordinadas a ele

ô as atribuições de políticas para agricultores familiares, até

Z्च então sob a órbita do Ministério da Agricultura, Pecuária e Abastecimento (MAPA). Ver, entre outros, Medeiros (2002).

ஸ ${ }^{2}$ Uso esse termo e não reforma agrária porque ele me parece mais adequado para indicar o caráter pontual da polí-

U tica de distribuição de terras, que foi feita, como veremos

$\supsetneq$ adiante, assentando famílias envolvidas em conflitos mais

intensos, seguindo a lógica do Estatuto da Terra, de 1964,

mas também facilitando a concentração fundiária nas áre-

J as de maior interesse dos grandes capitais. muito subjacentes no debate político e que voltaram à cena pública por meio de um novo pacto de poder. Neste novo contexto, os movimentos sociais tão ativos desde o final dos anos 1970 tiveram suas iniciativas políticas afetadas, com as organizações acossadas tanto pelos efeitos da crise econômica que vem desde 2008, quanto e, talvez principalmente, pela crescente dificuldade de diálogo com o Estado, de reconhecimento de suas demandas e em mobilizar suas bases. ${ }^{3}$ Mais recentemente, os efeitos da pandemia da Covid-19 só agravaram esse quadro.

O presente artigo explora aspectos dessas mudanças. Seu suposto é a necessidade de pensar os atores sociais como envolvidos em constantes reconfigurações e articulações tanto entre si, por meio de suas organizações de representação, quanto em disputas políticas com opositores e com o Estado. Iniciamos com um breve histórico das mudanças que atingiram o meio rural nas últimas décadas. Na sequência, discutimos a dinâmica política da representação das categorias agricultura familiar, trabalho assalariado e, por fim, as faces contemporâneas da dinâmica da disputa fundiária. Procuramos mostrar como essas categorias se entrecruzam e como a preocupação classificatória tende a esconder a complexa rede de relações que articula diferentes segmentos do campo e suas organizações e as vinculações entre rural e urbano, cada vez menos perceptíveis como universos estanques. Finalmente, tratamos do crescente protagonismo do agronegócio e suas implicações para as disputas no campo e para a reconfiguração da questão agrária.

\section{MODERNIZAÇÃO E EMERGÊNCIA DE NOVOS ATORES NO CAMPO}

Desde os anos 1950, mas em especial a partir das políticas empreendidas pelo regime

${ }^{3} \mathrm{O}$ tema da complexidade da relação Estado e movimentos sociais é tratado de forma bastante abrangente por Abbers; Von Bulow (2011). 
militar (1964-1985), o campo brasileiro vem passando por profundas alterações envolvendo modernização tecnológica; criação de instituições voltadas à pesquisa agropecuária, que tornaram possível, por exemplo, a ocupação dos cerrados, a introdução de novos cultivos - como a soja - e o fortalecimento de outros, com presença tradicional na pauta de exportações em novas bases produtivas, como é o caso da cana, café, algodão; instituição de mecanismos de crédito que facilitaram a inovação tecnológica, mas também levaram a um intenso processo de diferenciação social e econômica, ao endividamento e perda de bens por parte de segmentos de agricultores; aceleração da ocupação de novas áreas, em especial no Centro Oeste e Amazônia, mediante incentivos fiscais; estímulo ao turismo como empreendimento empresarial, atingindo áreas antes pouco exploradas (Delgado, 1985; 2012; Garcia; Palmeira, 2001; Palmeira; Leite, 1998).

Esse processo, em suas múltiplas dimensões, resultou em expropriação de diferentes grupos sociais que viviam no meio rural, tanto em áreas de exploração antiga, quanto nas que foram sendo incorporadas pelos investimentos de capital. Graças à mecanização do processo produtivo e à introdução de insumos químicos, tornaram-se desnecessários trabalhadores morando no interior das propriedades. ${ }^{4}$ Muitos deles, tendo que sair das fazendas, passaram a viver nas periferias das pequenas cidades interioranas e, arregimentados por empreiteiros, passaram a realizar tarefas variadas, sem contrato formal e, portanto, sem acesso a direitos trabalhistas (Graziano da Silva, 1981). ${ }^{5}$ Conhe-

${ }^{4}$ Colonos, moradores, agregados, parceiros, foreiros eram termos locais que indicavam situações em que o trabalhador vivia dentro da propriedade, tinha acesso a um pequeno lote de terra para plantar para sua subsistência, cuidava do produto principal da fazenda e ainda realizava uma enorme variedade de atividades de manutenção da propriedade, como limpeza de caminhos, recuperação de instalações etc. (Palmeira, 2009; Stolcke, 1986).

${ }^{5}$ Esses direitos foram assegurados desde 1963, com a aprovação do Estatuto do Trabalhador Rural, substituído pela Lei no 5.889, de 8 de junho de 1973, que incorporou várias cláusulas da CLT. O FGTS foi estendido ao campo pela Constituição de 1988 e a prescrição bienal (direito de recorrer à justiça até dois anos após a cessação do vínculo e não da violação do direito, como no caso dos demais cidos como volantes, boias-frias ou clandestinos, viviam (e vivem) entremeando ocupações temporárias nas áreas rurais, com outras igualmente precárias, nas áreas urbanas (construção civil, trabalhos domésticos). Longe de resquício do passado, a precarização do trabalho no campo manteve-se ao longo das décadas. ${ }^{6}$ Os investimentos turísticos em áreas antes relativamente isoladas, a valorização das terras próximas a centros urbanos provocando forte especulação tiveram efeitos semelhantes em áreas antes habitadas por posseiros, também contribuindo para o aumento de situações de pobreza e favelização. Da mesma forma, terras habitadas por povos indígenas foram cada vez mais incorporadas ao mercado de terras, resultando na sua expulsão ou mesmo dizimação de grupos inteiros.

Paralelamente e mostrando a complexidade dos processos em curso, ganhou visibilidade uma ampla camada de agricultores, em sua grande maioria proprietários de pequenos lotes de terra que, desde os anos 1970, passaram a inscrever suas demandas na pauta sindical. Enquadrados sindicalmente como trabalhadores rurais, foram pouco considerados nos debates sobre a questão agrária nos anos 1950 e 1960 e classificados como produtores de subsistência, sem maior relevância econômica ou política. No entanto, em especial parcelas dos que viviam no sul do país, descendentes de colonos migrantes, conseguiram aderir ao processo de modernização, intensificando a diferenciação social, com muitos perdendo terras, outros se integrando às agroindústrias que se fortaleceram nos anos $1970,^{7}$ outros ainda procurando sobreviver em condições adversas, combinando trabalhos na sua propriedade com venda de

trabalhadores) foi eliminada em 2000, quando foi igualado o prazo entre rurais e urbanos por meio de uma mudanca do inciso XXIX do artigo 7 da CF de 1988. Disponível em: http://www.contag.org.br/index.php? modulo=portal\&acao $=$ interna\&codpag $=386 \& a p=1 \& n w=1$. Acesso em: 20 jan. 2021.

${ }^{6}$ Ela se aproxima da situação que caracteriza o trabalho nos dias atuais, em diversos setores produtivos. Ver, entre outros, Antunes (2018).

${ }^{7}$ Com destaque para a produção frutas para conserva, uva, fumo e aves e suínos. Ver Wilkinson (1986). 
força de trabalho em fazendas ou mesmo em núcleos urbanos próximos. Por um lado, buscavam garantir renda, com a integração a mercados mais amplos, de forma a se proteger do risco de sucumbir às dívidas e ter que se desfazer das terras. Parcelas importantes desses agricultores eram uma das bases da Confederação Nacional dos Trabalhadores na Agricultura (Contag) e, em seus espaços, desenvolviam demandas por crédito e assistência técnica. ${ }^{8}$

Esses processos, nas suas diferentes formas, constituíram um grande número de trabalhadores sem acesso à terra. Se parte deles migrou para as cidades (grandes e pequenas), outros se organizaram, regra geral com apoio da Igreja Católica, por meio da Comissão Pastoral da Terra (CPT), e se reapropriaram de formas de luta desenvolvidas nos anos 1960, como ocupações e acampamentos para pressionar o Estado (Sigaud, 2000; 2005; Sigaud; Rosa; Macedo, 2010). Nesse quadro, assumir a identidade de "sem terra" não era apenas não ter terra, mas se colocar politicamente como demandante de acesso a ela, pressionando o Estado.

Frente a esse conjunto de mudanças, torna-se impossível pensar em trajetórias lineares de categorias: uma mesma família ou até mesmo um indivíduo pode estar em diferentes posições buscando melhores condições de reprodução social e econômica, o que colocou sensíveis desafios para a organização, tanto sindical, quanto sob a forma de "movimentos". สิ Desde os anos 1980, esses processos fi- caram visíveis como parte do crescimento das lutas sociais no país e das demandas por reconhecimento de novos atores, que produziam novas questões que se tornavam públicas (Ce$\dot{2}$ fai, 2001). Elas foram constitutivas do processo Æં de redemocratização e recolocaram a questão agrária na ordem do dia. Mesmo as greves de assalariados que se iniciaram em Pernambuco e,

${ }^{8}$ Essas demandas já estavam presentes no II Congresso

da Contag realizado em 1973. Pouco depois, essa entida-

de encomenda uma pesquisa a uma universidade para ter dados sobre a importância desses agricultores na produção de alimentos no país. Os resultados foram publicados em Graziano da Silva et al. (1978). Como veremos adiante, esse é ainda um dos importantes temas de disputa política. na primeira metade dos anos 1980, se estenderam por outros estados, não excluíam, em algumas situações, a demanda por acesso ao lote de terras como parte de suas reivindicações. Mobilizações de pequenos agricultores por melhores preços, crédito, direitos previdenciários tinham por horizonte, como antes apontado, por um lado, manter-se na terra e, por outro, inserir-se numa dinâmica de mercado que trazia o risco do endividamento e da pauperização.

A essas lutas somavam-se diferentes formas de resistências que buscavam assegurar o uso da terra segundo formas guiadas pelo costume, como é o caso do livre acesso aos babaçuais; aos castanhais; fundos de pasto; a defesa dos seringais; das lutas de posseiros em áreas de ocupação antiga. Nesse processo há substantivas novidades: se alguns desses atores emergentes já estavam organizados sindicalmente, outros questionavam as práticas sindicais e buscavam mudar seus rumos ou mesmo criavam novos caminhos organizativos, ao mesmo tempo em que afirmavam suas particularidades. Ou seja, no confronto com os que com eles disputavam terras e com políticas públicas que os desconheciam, traziam à luz concepções distintas de uso da terra e de propriedade, que não se enquadravam nas formas legais existentes e, de alguma forma, as colocavam em questão (Almeida, 2006).

Não se tratava de luta contra o latifúndio atrasado (embora às vezes fosse assim nomeada), mas o resultado de uma reconfiguração de atores e de formas de luta produzidas num novo contexto social, de intensa modernização, com crescente integração entre agricultura e indústria e intensa valorização de terras que passam a ser objeto de investimentos tanto produtivos, quanto visando atividades turísticas ou expansão urbana.

Desde o final dos anos 1970, a realização de sucessivos encontros de trabalhadores de diversas inserções colocou em relação essas diferentes concepções, que produziram aproximações e estranhamentos. Tratava-se de um momento de conformação de atores, mas tam- 
bém de disputas internas pela representação desses novos segmentos que emergiam e que traziam questões, nem sempre de equacionamento simples, uma vez que colocam em jogo diferentes concepções de direitos e diferentes modos de fazer valer suas demandas, em especial no que diz respeito a representações já estabelecidas, como é o caso da sindical. Nesse contexto, tanto a ação de organizações não governamentais quanto as da CPT se combinavam com diferentes vertentes dos movimentos e organizações, num período rico de experiências que valorizavam as identidades locais e suas particularidades, ao mesmo tempo em que buscavam a linguagem legal para reivindicar direitos (Medeiros, 2019).

Com a Constituição de 1988, marco de uma nova era da história brasileira em relação à democratização e ampliação de direitos (trabalhistas, à terra, à seguridade social, à educação), as lutas se ampliaram e passaram a usar a Carta Magna como referência para possibilidades de ampliação de direitos. Isso significou, além de trazer para o espaço público novas questões, também a construção de novas formas de relacionamento com o Estado, combinando a lógica do confronto com a da participação. O Estado deixava de ser percebido como um bloco monolítico e passava a ser olhado como espaço de múltiplas possibilidades de abertura de canais de diálogo e de formatação de políticas públicas, capazes de atender demandas várias (Abbers; von Bulow, 2011). No entanto, isso não se fazia sem filtros e seletividade (Offe, 1984).

Inovações em termos de mobilização se desdobraram em grandes manifestações nacionais, que levavam a Brasília milhares de trabalhadores de diferentes pontos do país para encontros e apresentação de demandas ao governo federal. Manifestações massivas como Gritos da Terra, Marcha dos Sem-Terra, Marcha das Margaridas, ocupações do Incra e de prédios públicos, mobilizações indígenas passaram a marcar o cenário político nacional, numa combinação de pressão e negocia- ção. Dessas iniciativas resultaram políticas que marcaram os anos 90 e o início dos anos 2000. Subjacentes a elas, cresceram disputas por representação e por formas de nomeação, diferenciando atores.

\section{AGRICULTORES FAMILIARES E REARRANJOS NA ORGANIZAÇÃO DOS TRABALHADORES}

Uma das principais mudanças das últimas décadas foi a afirmação política da categoria agricultura familiar, que provocou importantes rearranjos no sindicalismo rural e nas políticas públicas (Medeiros, 2010; Picolotto, 2014; Picolotto; Medeiros, 2017). Já no final dos anos 1980 e início dos 90, a categoria ganhou força a partir de pelo menos dois processos que se entrecruzavam: por um lado, setores dos chamados pequenos agricultores canalizaram suas energias para fortalecer as "oposições sindicais", articulação de sindicalistas críticos às práticas da Contag, consideradas tímidas e incapazes de produzir mudanças significativas na situação dos trabalhadores. Essas "oposições", no embate sobre adesão às recém-criadas centrais sindicais, organizaram-se na Central Única dos Trabalhadores (CUT), criando no seu interior uma Secretaria e, logo depois, um Departamento Nacional de Trabalhadores Rurais, onde os pequenos agricultores tinham forte presença. Esse reordenamento de representação não pode ser compreendido sem considerar os diálogos com agências internacionais, facilitados pelas relações com a Igreja Católica e com organizações não governamentais (Medeiros, 2014). As iniciativas internas ao campo sindical se cruzavam com debates acadêmicos e muitos intelectuais eram convocados para atividades de assessoria às organizações (palestras, seminários, acompanhamento de reuniões, pesquisas). Tratava-se de um debate tanto político como conceitual, em que estava em discussão o estatuto da categoria "pequeno agricultor", a de "camponês" 
e a de "agricultor familiar" (em oposição ao grande produtor, de caráter patronal).

Em que pese a valorização da dimensão familiar da produção, o sindicalismo de trabalhadores rurais se apoiava na definição legal que delimitava sua base: pelo Decreto-Lei 1.166, de 15 de abril de 1971, era considerado pequeno produtor aquele que trabalhasse em regime de economia familiar, com área igual ou inferior a um módulo rural, podendo contar com ajuda eventual de terceiros. No entanto, a diferenciação que marcou a agricultura, em especial no sul do país, afetou fortemente esse segmento e trouxe ainda nos anos 1970 discussões em torno da possibilidade de criação de uma terceira faixa sindical, composta por produtores de base familiar, que não se consideravam representados nos sindicatos de trabalhadores, com sua amplitude, nem pelos sindicatos patronais, controlados pelos grandes produtores.

Não temos como precisar quantitativamente, mas diversos sindicatos que constituíram as oposições sindicais no final dos anos 1970 e início dos anos 1980 tinham como sua base segmentos de agricultores integrados a mercados, com forte peso na base sindical do DNTR/CUT. No entanto, esse segmento também era representado na Contag. Havia, pois, além de um recorte que envolvia concepções políticas sobre o sindicalismo, também disputas políticas locais e regionais. Como resultado, já no final dos anos 1990, surgiu uma ন్ Federação da Agricultura Familiar em Santa ণ Catarina, que se se desdobrou numa federação regional e, no início dos anos 2000, na criação da Federação Trabalhadores na Agricultura Familiar do Brasil (Fetraf-Brasil), transforma¿. da, em 2016, na Confederação Nacional dos கं Trabalhadores e Trabalhadoras na Agricultura $>$ Familiar do Brasil - Contraf/Brasil/CUT), em 2020 contando com mais de 900 sindicatos e organizada em 20 estados ${ }^{9}$.

A disputa por representação desse segmento se torna mais complexa ainda a partir da

9 Disponível em: https://contrafbrasil.org.br/conteudo/ quem-somos/. Acesso em: 20 jan. 2021. constituição, no final dos anos 1990, do Movimento dos Pequenos Agricultores, que logo se vincula à Via Campesina e se coloca no cenário político a partir da identidade camponesa, defendendo uma agricultura de bases agroecológicas, fundada no princípio da soberania alimentar, hídrica, mineral, energética e territorial. Esse conjunto de princípios funda o "Plano Camponês", "um programa estratégico que pressupõe o campesinato e os povos originários e tradicionais como a base do desenvolvimento do campo". ${ }^{10}$

Com a Constituição de 1988 e sua regulamentação por meio da lei 8629, de 23 de fevereiro de 1993, conhecida como "Lei Agrária”, as ambiguidades envolvidas no enquadramento sindical se multiplicaram. Pela Constituição, foram criadas três categorias de propriedade no campo, definidas em termos de tamanho (pequena, média e grande), substituindo as categorias presentes no Estatuto da Terra (minifúndio, latifúndio por exploração, latifúndio por dimensão e empresa rural). A lei de 1993 definiu a pequena propriedade como aquela que tinha até quatro módulos; média, quando possuía de quatro a quinze módulos; e grandes, as com mais de quinze módulos. Pelas normas do enquadramento sindical, eram considerados trabalhadores rurais os que tinham até um módulo, o que já não correspondia à base real do sindicalismo. Esse impasse foi parcialmente resolvido pela Lei 9.701, de 17 de novembro de 1998, que enquadrou como trabalhador rural quem tinha até dois módulos. Importante lembrar que se tratava de uma disputa que envolvia também bases dos sindicatos patronais e que se relacionava com as possibilidades de acesso ao Programa Nacional de Fortalecimento da Agricultura Familiar (Pronaf), criado em 1995 e primeira política agrícola direcionada especificadamente para agricultores familiares, definidos com base na lei de 1993 (Schneider; Cazella; Mattei, 2004). Impulsionada pela criação dessa política, a categoria "agricultor familiar" progressiva-

${ }_{10}$ Disponível em: https://mpabrasil.org.br/plano-campones/. Acesso em: 15 jan. 2021. 
mente se generalizou, ganhou contornos mais claros e sucessivas regulamentações, sendo a mais importante delas a lei de agricultura familiar (lei 11.326 de 24 de julho de 2006). Nela, consideravam-se como tal os que praticassem atividades no meio rural, detendo área com, no máximo, quatro módulos fiscais (ou seja, bem mais que a referência para o enquadramento sindical); utilizassem predominantemente mão-de-obra da própria família e tivessem renda familiar predominantemente originada de atividades econômicas vinculadas ao estabelecimento; dirigisse o estabelecimento com sua família. Entre seus beneficiários foram incluídos silvicultores; aquicultores; extrativistas; pescadores; povos indígenas e integrantes de comunidades remanescentes de quilombos rurais e demais povos e comunidades tradicionais, abrangendo, pois, grupos sociais que iam bem além das tradicionais bases sindicais. Essa legislação se desdobrou em uma série de programas voltados para determinados segmentos ou temas considerados sensíveis. ${ }^{11}$

Como apontado por Wesz Jr. (2021, p. 95), no entanto, a principal linha do Pronaf, a de custeio, foi progressivamente sendo concentrada em contratos de maior valor, "sobretudo naqueles com mais de R $\$ 50$ mil, que representavam 31\% em 2014 e passaram para 47\% em 2018, enquanto nos contratos de menos de $\mathrm{R} \$ 30$ mil esses números quase se invertem, pois, no mesmo período, passa de $46 \%$ para $35 \%$ ”. O mesmo autor mostra que, embora os que recebiam Pronaf B fossem o grupo mais numeroso (55\% dos agricultores familiares no Censo Agropecuário de 2006 e 70\% no Censo Agropecuário de 2017), fizeram 36\% dos contratos em 2018. Os que recebiam Pronaf A tinham 21\% dos recursos do Pronaf em 2000 e caem para $0,8 \%$ em $2018 .{ }^{12}$ Ou seja, há uma

${ }^{11}$ Dentre eles, o Seguro da Agricultura Familiar, o Programa de Garantia de Preço da Agricultura Familiar, o Programa de Aquisição de Alimentos (PAA), o Programa Nacional de Alimentação Escolar (Pnae), o Programa Nacional de Produção e Uso do Biodiesel (Pbio), o Programa Nacional de Assistência Técnica e Extensão Rural (Pronater), o Programa Desenvolvimento Sustentável de Territórios Rurais (Pronat), Programa Territórios da Cidadania (PTC).

${ }^{12} \mathrm{O}$ Pronaf A é formado por agricultores familiares assentados pelo PNRA ou beneficiários do PNCF; o Pronaf B é a linha significativa diferenciação no interior da camada legalmente identificada como "agricultor familiar”, e muitos sequer acessam o Pronaf. Ainda segundo Wesz Jr., o decreto 9064, de 31 de maio de 2017, que regulamentou a lei de 2006, criou a Unidade Familiar de Produção Agrária e tirou de seu âmbito categorias como pescadores, aquicultores, extrativistas, silvicultores, quilombolas e indígenas, o que afetou diretamente o número de estabelecimentos agropecuários familiares aptos a receber o Pronaf. ${ }^{13}$ Além disso, há que se considerar que muitos agricultores não foram classificados como familiares por terem renda provenientes de atividades fora da propriedade, por um lado, ou, por outro, pelo aumento do uso de mão de obra contratada (Del Grossi et al. 2019).

Esses dados indicam transformações internas na categoria agricultura familiar e trazem desafios ainda pouco estudados em termos do que eles representam em termos de organização sindical. A diferenciação interna se reflete no crescente uso acusatório pelos movimentos sociais, em especial os ligados à Via Campesina, da categoria agronegocinho, referindo-se aos segmentos que crescentemente se integram ao agronegócio. Incidem ainda nas disputas no interior do Ministério da Agricultura, Pecuária e Abastecimento (Mapa) em torno da unificação de políticas de apoio ao desenvolvimento do agronegócio como um todo e não a determinado grupo de agricultores. Exemplo disso são as recorrentes afirmações da ministra Thereza Cristina sobre a existência de uma só agricultura. ${ }^{14}$ Também aparece quando se analisa como esses conflitos se refletem localmente. ${ }^{15}$

de microcrédito, que inclui famílias com renda bruta anual de até R\$ 23 mil e sem emprego de trabalho permanente.

${ }^{13}$ A Unidade Familiar de Produção Agrária recobre famílias que explorem uma combinação de fatores de producão, com a finalidade de atender a própria subsistência e à demanda da sociedade por alimentos e por outros bens e serviços, e que resida no estabelecimento ou em local próximo a ele.

14 Disponível em: https://terezacristinams.com. br/2019/01/02/tereza-cristina-da-posse-a-secretarios-com-ministerio-fortalecido/. Acesso em: 15 jan. 2021

${ }^{15}$ Um interessante estudo que mostra a circulação de lideranças entre diferentes organizações a partir de disputas locais é o de Teló (2014). 
Ou seja, estamos num cenário de disputas por representação e por projetos políticos diferenciados, que trazem para o centro do debate o lugar dos agricultores mais pobres, pensando não só em termos de renda, mas também de sua capacidade de construir representação política. Olhando as pautas sindicais, é possível afirmar que o sindicalismo fala pelos agricultores familiares mais estabelecidos, público, por excelência, do Pronaf. O MPA, por sua vez, fala para um grupo de agricultores com organização mais delimitada e que buscam a construção de um novo modelo de agricultura com base em princípios agroecológicos, recuperando o termo camponês para referenciar um modo de vida. Trata-se de indagar sobre quem fala por esses segmentos mais empobrecidos, à margem ou com acesso limitado ao Pronaf.

\section{AS NOVAS CONFIGURAÇÕES DOS ASSALARIADOS RURAIS}

Se, no início da década de 1980, o Brasil presenciou um ciclo significativo de greves de assalariados rurais, os anos que se seguiram foram marcados por paralizações pontuais e mobilizações locais de assalariados. Ao mesmo tempo se acumularam as reclamações legais e as denúncias referentes à progressiva deterioração das condições de trabalho. ${ }^{16}$

Uma dificuldade importante na repreনิ sentação sindical desse segmento refere-se à

ปิ ${ }^{16}$ Como indicadores dessa precarização são recorrentes as - queixas sobre exposição a agrotóxicos sem a devida pro-

$\bullet$ teção; movimentos repetitivos que implicam em lesões;

I condições exaustivas de trabalho; doenças degenerativas,

$\dot{2}$ temas que vêm sendo apontados quer por trabalhos acadê-

micos (Verçoza, 2018; Silva, 2013) quer por denúncias de

๗ organizações não governamentais como é o caso da Repór-

$>$ ter Brasil (https://reporterbrasil.org.br/). A elas se somam

i os casos que podem ser enquadrados como trabalho escra-

- vo, objeto de constantes denúncias pelos sindicatos, pela

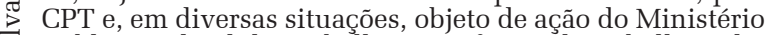

तూ Público Federal do Trabalho. Essa forma de trabalho é de-

finida pelo Código Penal (art. 149), como aquela em que

IJ estão presentes condições degradantes, com violação de

J direitos fundamentais que colocam em risco a saúde e a

vida do trabalhador, jornadas exaustivas, trabalho força-

do, ameaças físicas e psicológicas, servidão por dívida etc.

安 Nessas situações limítrofes são evidentes as dificuldades

U de organização. transformações sofridas pela agricultura brasileira antes descritas. O fato de os contratos terem curta duração e de que os trabalhadores circulam em busca de trabalho, traz, por si só, significativos desafios para a organização e para a definição de qual a base sindical, em especial considerando que há migrações sazonais de longa distância (Menezes, 2014; Novaes; Alves, 2007; Silva, 1999). Como se vincular ao sindicato de base municipal se a permanência numa determinada localidade é curta, muitas vezes sem contrato formalizado e seguida de busca de trabalho em outros locais? Como organizar a base sindical se ela é fluida e, em diversas situações, como no caso da cana-de-açúcar, os trabalhadores migrantes ficam alojados no interior das usinas sob estrito controle da empresa? A isso, acresce-se uma diferenciação interna entre os assalariados, que ainda merece estudos aprofundados, com a constituição de um setor de trabalhadores que opera com máquinas e equipamentos sofisticados, que exigem habilidades específicas e geram profundas distinções com os trabalhadores considerados braçais.

Esses elementos fragilizaram a representação sindical dos assalariados, ao mesmo tempo em que se verificava o fortalecimento dos agricultores familiares, objeto, como vimos, desde meados dos anos 1990, de políticas específicas de valorização e reconhecimento. $\mathrm{Ou}$ seja, perdem pouco a pouco o protagonismo político, embora, se nos basearmos na documentação sindical, em especial nos congressos da Contag, a pauta de reivindicações dos assalariados está sempre presente. ${ }^{17}$

Com a Constituição de 1988 e a instituição da liberdade e autonomia sindical, ganhou corpo a tentativa, no estado de São Paulo, de se formar uma federação sindical específica, a Federação de Empregados Rurais e Assalariados do Estado de São Paulo (Feraesp) que, no

${ }_{17}$ Já desde o final dos anos 1970, nos bastidores sindicais, havia um tensionamento com pequenos agricultores que empregavam assalariados, considerando que ambos integravam a mesma base sindical subsumidos numa ampla categoria politicamente construída pela Contag (Palmeira, 1985). 
entanto, por muito tempo, sequer foi reconhecida como representante legal de sua categoria em negociações coletivas. Sua existência tensionava a representação sindical contaguiana e, de alguma forma, trazia à luz as dificuldades de representação do segmento.

Em que pese a dificuldade de reconhecimento legal e, portanto, de poder representar suas bases nas negociações salariais, a Feraesp firmou-se em algumas áreas do estado e, em pouco tempo, já mostrava as contradições presentes na categorização formal dos empregados rurais: um dos marcos de sua atuação foi a ocupação de terras, sendo bem sucedida na formação de alguns assentamentos rurais, passando a falar também por assentados, ou seja, pequenos agricultores/agricultores familiares, ao mesmo tempo em que buscava se tornar representação efetiva dos assalariados dos canaviais e de colhedores de laranja de São Paulo (Coletti, 1998; Thomaz Jr., 2004).

Apesar das tentativas de filiação ao sistema Contag, a Feraesp não foi aceita, em nome da manutenção da unicidade sindical, tida pela Contag como um valor, para além das possibilidades legais de reconhecimento da representação dos assalariados. ${ }^{18}$

Essas tensões, que se acumularam ao longo dos anos e acompanharam o crescimento da força política dos agricultores familiares, culminaram na chamada dissociação sindical em 2016, momento em que a representação sindical tradicional contaguiana se cinde e cria-se um sindicalismo que representa os assalariados rurais (Confederação Nacional dos Trabalhadores Assalariados Rurais, Contar) e outro que representa os agricultores familiares, a Contag (Picolotto, 2018). ${ }^{19}$

A partir da reforma trabalhista (lei

${ }^{18}$ Essa tentativa foi feita também pela Federação dos Trabalhadores da Agricultura Familiar de Santa Catarina (Fetrafesc), recusada pelas mesmas razões (Medeiros, 2014).

${ }^{19}$ Como mostra Picolotto (2018), desde 2014 o Ministério do Trabalho e Emprego (MTE) manifestou entendimento de que podem existir duas categorias sindicais específicas (assalariados rurais e agricultores familiares) dentro da "categoria eclética de trabalhador rural" (p. 203). Essa manifestação foi decisiva para que a dissociação pudesse ocorrer legalmente.
13.467/2017, que alterou diversos pontos da CLT) e da lei 13.429/2017, que permitiu a terceirização do trabalho para todos os tipos de atividade, a situação dos trabalhadores tornou-se ainda mais precária. ${ }^{20}$ Sem trazer grandes novidades para as áreas rurais, uma vez que a marca constante foi a precariedade contratual, a reforma permitiu a continuidade de uma situação de extrema carência de direitos dos rurais. Acresça-se a isso a extinção do Ministério do Trabalho em 2019 (MP 870, aprovada pelo Senado em 28/5/2019) e a transferência de suas atribuições entre os Ministérios da Economia, Justiça e Cidadania, o que aumenta a insegurança jurídica dos assalariados e as dificuldades de fiscalização de situações irregulares. Tais medidas colocam ainda maiores dificuldades para a Contar, que se organiza num momento extremamente adverso para os trabalhadores.

\section{A LUTA PELA TERRA E OS NO- VOS ATORES}

No que diz respeito à questão fundiária, de luta contra o "latifúndio atrasado" que marcou os anos 50/60, passou-se progressivamente à crítica ao agronegócio, à progressiva incorporação da dimensão ambiental, e da defesa de uma alimentação saudável, isenta de agroquímicos, dotando a questão agrária de novos significados. São novos enquadramentos que reorganizam os atores. ${ }^{21}$

Como apontado anteriormente, o início dos anos 1980 foi marcado pela emergência de ocupações e acampamentos como forma mais visível de luta por terra, em especial nas áreas mais modernizadas, como o Sul e o Sudeste, estendendo-se depois para todo o país. Elas tiveram efeitos importantes na Assembleia Nacional Constituinte e resultaram na incor-

${ }^{20}$ Uma análise dessas mudanças e suas implicações para o mundo do trabalho pode ser encontrada em Krein (2018).

${ }^{21}$ A respeito da importância produção de novos enquadramentos para a luta política ver, entre outros, Benford; Snow, 2000. 
poração ao texto constitucional do tema da reforma agrária, vinculada à definição de que a terra tem uma função social, recuperando o que fora estabelecido no Estatuto da Terra. No entanto, os debates em torno do tema levaram para dentro da Constituição uma contradição. Por um lado, há a definição da função social e, por outro, a assertiva de que terras produtivas (assim como a pequena e média propriedades) não podem ser desapropriadas. ${ }^{22} \mathrm{~A}$ regulamentação da Constituição pela chamada Lei Agrária de 1993, anteriormente mencionada, de alguma forma abriu caminho para a retomada das ocupações e acampamentos, com base na lei: as organizações escolhiam para serem ocupadas propriedades que poderiam ser classificadas como improdutivas. Cabia ao Incra, por meio de uma série de procedimentos técnicos (vistorias, uso de índices etc.) definir se a propriedade poderia ser desapropriada ou não. ${ }^{23}$

Essas medidas fizeram com que crescesse a pressão sobre a terra, à medida que as desapropriações e assentamentos ocorriam, mostrando para os movimentos a eficácia das formas de luta escolhidas. A própria dinâmica da luta fortaleceu a constituição de áreas com vários assentamentos próximos, em especial nas regiões onde havia crise das lavouras tradicionais, como é o caso da cana em algumas áreas do Nordeste e do Rio de Janeiro (Leite et al. 2004). Mas também consolidou a lógica das desapropriações caso a caso, fora da perspectiন va de uma reforma agrária massiva ou mesmo ๙ de seleção de áreas prioritárias, que continuava a ser demandada pelas organizações que ¿ estavam à frente das ocupações. As crescentes $\because$ dificuldades para obtenção de terras para as¿. sentamentos levaram também à desmobilizaகే ção, uma vez que a luta pela terra se alimenta

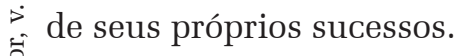

${ }^{22}$ Para uma discussão mais exaustiva do tema, ver Medei$\operatorname{ros}(2002)$

I ${ }^{23}$ A base desse cálculo são os índices de produtividade. Os

disponíveis no início dos anos 2000 foram calculados com

base no Censo de 1975, momento em que a modernização

se iniciava. Tentada no governo Lula, a sua atualização, que permitiria a ampliação das propriedades passíveis de desapropriação, não se viabilizou.
Do ponto de vista da representação política dos trabalhadores do campo, também nessa esfera ocorreu importante divisão. A emergência do MST, como grupo mobilizado, sem formalidades de registro jurídico contrapunha-se à formalidade da representação sindical da Contag. Por outro lado, se no final dos anos 1970 a Contag falava em ocupar, no período da redemocratização optou por práticas mais negociadoras, em especial no início da Nova República quando alguns de seus quadros de assessoria ocupavam postos no Incra. Do ponto de vista político, isso implicou em assentamentos que se colocavam publicamente como "do MST", do "sindicato", "da Feraesp" ou de outras organizações que se formaram ao longo dos últimos trinta anos. Não foram poucas as situações de assentamentos divididos entre diferentes forças, disputando apoios e recursos.

Para além das disputas por representação dos que demandam terra, também estiveram em jogo nos últimos anos as possibilidades de investir nos assentamentos em termos de arranjos produtivos e de relações com outros segmentos sociais. Assim, se para o sindicalismo rural o acesso à terra se configurava como ponto de chegada, para o MST ele era definido como um ponto de partida para uma transformação mais ampla. Num primeiro momento, para esta organização, tratava-se de mostrar como os assentamentos podiam ser produtivos, de forma a afirmar publicamente o sucesso da reforma agrária. No entanto, articulações com outras organizações, em especial a Via Campesina, levaram à busca de novas possibilidades produtivas e construção de novas alianças políticas que trouxeram profundas inovações. O exemplo mais significativo talvez seja o abandono da concepção de que os assentamentos deveriam ser geridos de forma a explorar o potencial produtivo das grandes unidades coletivas formadas. Com efeito, desde o final dos anos 1990, a valorização de práticas agroecológicas de produção levou o MST a buscar o estímulo à recuperação de técnicas tradicionais, de produtos locais, alinhavados 
com formas cooperativas de gestão de produção, de uso de equipamentos ou de venda de produtos. Ao mesmo tempo, ia se gestando um debate sobre qualidade do alimento, sobre alianças com consumidores que levaram a um modelo de reforma agrária que vai além da distribuição de terra e está profundamente alinhada com a discussão dos riscos ambientais, adotando a agroecologia como modelo produtivo (Lerrer; Medeiros, 2014). São esses elementos que passam a compor o que o MST chama hoje de "reforma agrária popular".

No entanto, a questão fundiária não se expressa só na luta de sem-terra mas também na dos posseiros. Não por acaso, nos anos 1990 ganha relevo um antigo debate que converge com o da reforma agrária que é o da regularização fundiária, ou seja, o reconhecimento da propriedade desses segmentos, dando-lhes o título legal. Esse debate foi particularmente fértil no governo Lula, quando o II PNRA colocou o tema na sua agenda. Já nesse momento, estava em jogo quem poderia ter seu título regularizado. Assim, da proposta inicial de regularizar um módulo, as disputas políticas levaram à ampliação desse limite. Nos dias de hoje, a proposta de titulação amplia o limite das terras legalizáveis, indicando o que o que está efetivamente em jogo é a legalização das ocupações ilegais de terra, conhecida como grilagem, denunciada quer pelo sindicalismo, quer com bastante intensidade pelo MST.

Finalmente, há que se destacar a progressiva incorporação de luta pela demarcação de terras indígenas, de territórios quilombolas, caiçaras e demais comunidades tradicionais na definição dos termos da questão agrária, levando a que o debate em torno da questão agrária incorporasse também o tema das "terras tradicionalmente ocupadas” (Almeida, 2006). A entrada desses novos atores, inicialmente localmente organizados, mas cada vez mais criando articulações nacionais e internacionais, traz outros componentes ao debate fundiário que o levam a ultrapassar os limites do produtivo: entram em questão novas compreensões sobre o significado da terra, como lugar da vida dos antepassados, das tradições, trazendo para o centro do debate o tema dos territórios. Não se trata de uma terra que possa ser trocada ou vendida. No cerne desse debate, a questão fundiária se cola à questão ambiental.

Também foram se constituindo formas de diálogo entres essas diferentes concepções, demarcando um novo momento de interconhecimento. Nessa direção, teve grande significado o I Encontro dos Povos da Terra, da Floresta e das Águas, realizado em 2012, e que, pela primeira vez na história brasileira, ensaiou construir uma unidade política entre grupos sociais bastante diferenciados e, inclusive, recortados por disputas entre si no plano local.

Ao longo desses anos, foram assentadas cerca de um milhão de famílias e reconhecidos direitos territoriais de diversos grupos sociais. No entanto, os índices de concentração fundiária pouco se modificaram. Ou seja, se, por um lado a terra era distribuída num local, ela era apropriada e concentrada nas regiões de avanço da agricultura moderna. Para avançar nessa discussão é importante romper os limites estritos da análise da representação política dos trabalhadores rurais e pensá-la lado a lado com o processo de crescimento e legitimação do que hoje se chama de agronegócio.

\section{DIMENSÕES POLÍTICAS DO AGRONEGÓCIO}

As últimas décadas não foram anos somente de reconfiguração dos trabalhadores do campo e das suas formas de organização. O mesmo processo que os diferenciou tanto econômica como politicamente também afetou a representação dos interesses ligados à terra e às novas formas de produção que se instauraram nas últimas décadas. Como já apontado, a modernização tecnológica da agricultura provocou avanços na agroindustrialização, voltada para a produção tanto para o mercado interno como externo. Esses processos levaram a uma 
crescente valorização de terras, em especial nas áreas novas, ainda pouco exploradas pelo capital. Como mostra Bruno (2010), também se multiplicaram as associações por produto e multiproduto, gerando formas de representação de interesse mais particulares, que se desenvolvem paralelamente à representação sindical oficial. Ao mesmo tempo, a pressão por terra, com acampamentos e ocupações e o anúncio, em 1985, num congresso de trabalhadores, da proposta do $1^{\circ}$ Plano Nacional de Reforma Agrária, resultou em novas iniciativas políticas dos setores patronais. É nesse momento que surge a União Democrática Ruralista (UDR), que se colocava contra o Plano e defendia abertamente o uso da violência nas ocupações de terra em nome do direito de propriedade. Sob liderança de alguns de seus quadros presentes no Congresso Nacional, foi possível a introdução de uma trava à reforma agrária na Constituição de 1988, como apontado anteriormente.

No entanto, sob a égide da Constituição, que reconhecia uma série de direitos e parecia inaugurar tempos democráticos, o discurso da UDR deixou uma forte marca de apologia da violência, da negação da negociação como caminho de entendimento para as demandas dos trabalhadores rurais, completamente frustradas com os parcos resultados do I PNRA (Medeiros, 2002). Não por acaso, no início dos anos 1990 se inicia uma outra articulação política, centrada na valorização de um setor 太ิ agropecuário que se advoga capaz de atender Nิ às necessidades de produção de alimentos, $\stackrel{\circ}{\circ}$ que se faz ver publicamente pela sua dimensão produtiva, articulando industrialização e distribuição de produtos agropecuários. Por $\dot{2}$ esse caminho, garantem seu protagonismo में político, projetando uma nova imagem a par$\vec{t}$ tir da valorização do termo complexo agroindustrial, na sua versão em inglês agribusiness, logo traduzida para agronegócio (Bruno, 2010. Para tanto, foram marcos tanto a produção de expressões intelectuais do setor, como é o caso do livro Complexo Agroindustrial - o agribusiness brasileiro (Araújo; Wedekin; Pinazza,
1990), que chamava a atenção para as modernas e complexas inter-relações entre cidade e campo e para a necessidade de "enxergar o sistema como um todo, de reconhecer o enorme crescimento da interpendência da agricultura com outros setores econômicos" (Araújo et al. 1990). Defendia ainda que as políticas para a agricultura deveriam ser desenhadas de forma a ultrapassar a dimensão setorial. Logo depois, em 1993, foi criada a Associação Brasileira do Agronegócio (Abag), com laços com instituições de pesquisa, como é o caso do Pensa (Centro de Conhecimento em Agronegócios), ligado à faculdade de Economia e Administração da USP e, depois, o Cepea (Centro de Estudos Avançados em Economia Aplicada) da Esalq/USP. Seu lançamento oficial foi no Congresso Nacional. Na ocasião foi lançado o livro Segurança Alimentar: uma abordagem de agribusiness, de autoria da nova entidade. Inicia-se então uma etapa mais pública do debate em torno de quem produz alimentos para a sociedade brasileira. Na visão da Abag dependia do agribusiness a segurança alimentar do país, "pedra fundamental de seu desenvolvimento como sociedade justa” (Abag, 1993, p. 9).

Esse foi um momento de crescimento do debate político em torno da pobreza e da fome e marcado pela criação do Conselho Nacional de Segurança Alimentar (Consea), ainda no governo Itamar Franco e pelas discussões no interior do chamado "governo paralelo", organizado ao redor do candidato derrotado nas eleições presidenciais de 1989, Luis Inácio Lula da Silva. ${ }^{24}$ Esses fatos são reveladores do campo de disputas que se estabelecia e onde a Abag buscava ganhar força, deslocando o foco do debate sobre a violência para a questão da produção, desta vez para o abastecimento interno, mas também de exportação, destacando a sua importância na economia brasileira.

Agregando não só produtores, mas também empresas do setor de processamento e

${ }^{24}$ Em janeiro de 1995, o governo Fernando Henrique Cardoso criou o Programa Comunidade Solidária e extinguiu o Consea. O órgão foi restabelecido em 2004. 
distribuição, agentes financeiros e centros de pesquisa (Abag, 1993), a Abag indica um processo de reconstrução da dinâmica de representação do setor. De acordo com Lerrer (2020, p. 276-277), foi por meio do termo "agronegócio" que este setor do patronato rural passou a construir uma nova imagem que se consagrou, repercutindo para a sociedade brasileira uma ideia que associa essa palavra à modernização, eficiência econômica, competitividade, domínio tecnológico e produtividade.

Desde então, forjou-se uma hegemonia que aparentemente tira a questão da propriedade do centro do debate, uma vez que o importa é que ela seja produtiva e articulada nessa cadeia, que seja capaz de produzir alimentos e colocar o Brasil numa posição de destaque no cenário internacional de produção agrícola. No entanto, como a própria expansão do agronegócio depende da disponibilidade de terras, o tema fundiário é uma dimensão central, embora não claramente explicitada nas autojustificativas do segmento.

Como aponta José Renato Porto (2014, p. 27), apoiando-se em Foucault,

Mais do que simplesmente revigorar-se como um grupo de interesse, conquistando (ou reconquistando) de maneira progressiva espaços no Legislativo, no Executivo, e executando pressão de forma significativa também no Judiciário, o agronegócio encampa hoje um poderoso 'discurso de verdade' (Foucault, 2010; 2011), capaz de atrelar elementos cuja força de persuasão é enorme. Dentre esses elementos, destacam-se, por exemplo, (i) a disputa pela ideia de "sustentabilidade", (ii) a narrativa da modernização, (iii) a bandeira do combate à fome, e (iv) mais recentemente, parece figurar também na linha argumentativa dos representantes do agronegócio uma defesa incólume da legalidade, dos princípios democráticos, do "Estado de Direito", obviamente não pelas afinidades às bases desses conceitos, mas sim como uma maneira eficiente de travestir os interesses e as práticas dos agronegócios. Essas dimensões, quando apropriadas, entrelaçadas e postas a serviço de determinados interesses específicos, figuram como metáforas mobilizadoras muito eficientes, capazes de convencer a opinião pública e legitimar a expansão de um modelo de produção agrícola e, por extensão, do próprio grupo político ligado ao agronegócio.

Não por acaso, cresce a disputa em torno de quem produz alimentos criando uma polarização entre agronegócio e agricultura familiar, que se coloca como o segmento que coloca alimentos na mesa dos brasileiros. Ao lado da disputa por números, ganha peso, como apontado, a tese de que há uma só agricultura. Desdobramento político dessa concepção foi a extinção do Ministério do Desenvolvimento Agrário em 2016 e a transferência de suas funções tanto relacionadas à agricultura familiar, quanto a assentamentos rurais e questões fundiárias ao Ministério da Agricultura. Fechando o círculo, não por acaso uma das expressivas lideranças da antiga UDR passa a ocupar o cargo de Secretário Nacional de Assuntos Fundiários desse mesmo Ministério.

\section{CONSIDERAÇÕES FINAIS}

Nos últimos 40 anos, os trabalhadores do campo se reorganizaram sob diversas formas, construíram formas de representação diversas, ocuparam a cena política com suas mobilizações e demandas. Para além dos temas tratados neste artigo, trouxeram à luz identidades territoriais, temas como gênero e geração, participação política. Passaram a integrar organizações internacionais, num processo conhecido como "globalização desde baixo" (Vieira, 2012). Foram anos de muitas trocas e disputas, mas que deram a conhecer suas demandas, diversidades e em especial buscaram fazer valer direitos como produtores, bem como trouxeram a debate direitos territoriais. Não se pode compreender essas disputas sem considerar o peso das mudanças, a crescente hegemonia do agronegócio e sua capacidade de construir um discurso com enorme poder de verdade que se difunde na sociedade, mas que também gera outros, quando são colocados à luz os temas ambientais que, cada vez mais, se impõem e 
obrigam o próprio agronegócio a reconstruir seus argumentos.

Os anos recentes mostraram uma forte pressão sobre as lutas no campo. As demandas foram questionadas em várias frentes, a institucionalidade que canalizava boa parte delas sofreu um rápido processo de desmonte, deixando os diferentes grupos de trabalhadores com poucos canais de interlocução, invertendo a lógica que marcou o início deste século. Voltou-se a um processo de trabalho interno, com atividades de formação e reflexão sobre os dilemas do presente, marcado para além dessas mudanças também pelos efeitos da pandemia.

Estamos vivendo um novo momento de silenciamento, face recorrente das lutas dos trabalhadores rurais brasileiros. No entanto, o crescente alinhamento com os temas ambientais, o debate em torno da alimentação saudável, trazendo ao centro da discussão novas formas de produzir, resignificando tradições, alimentos locais, circuitos curtos de comercialização de alimentos, valorização de sementes tradicionais, negando o uso de agrotóxicos e transgênicos e impondo o debate sobre a produção agroecológica, bem como a afirmação dos territórios num momento em que a financeirização da terra avança e em que ela se coloca cada vez mais como mercadoria, anunciam embates futuros.

Recebido para publicação em 14 de fevereiro de 2021 Aceito em 09 de abril de 2021

\section{REFERÊNCIAS}

ABAG. Segurança alimentar: uma abordagem do agribusiness. São Paulo: Abag, 1993.

Æ ABBERS, R.; VON BULOW, M. Movimentos sociais na teoria e na prática: como estudar o ativismo através da fronteira entre Estado e sociedade?. Sociologias, Porto Alegre, v. 13, n. 28, p. 52-84, 2011.

ALMEIDA, A. W. B. Terras de quilombo, terras indígenas, "babaçuais livres", "castanhais do povo", faxinais e fundos de pasto: terras tradicionalmente ocupadas. Manaus: PPGSCA-Ufam, 2006.

ANTUNES, R. Adeus ao trabalho?: ensaio sobre as metamorfoses e a centralidade do mundo do trabalho. São Paulo: Cortez, 2018.
ARAÚJO, N. B.; WEDEKIN, I.; PINAZZA, L. A. Complexo agroindustrial: o agribusiness brasileiro. São Paulo: Agroceres, 1990.

BENFORD, R.; SNOW, D. Framing process and social movements: an overview and assessment. Annuary Review of Sociology, Palo Alto, v. 26, p. 611-39, 2000.

BRUNO, R. Um Brasil ambivalente. Rio de Janeiro: Mauad e Edur, 2010.

Agronegócio e novos modos de conflitualidade. In: FERNANDES, B. M. Campesinato e agronegócio na América Latina: a questão agrária atual. São Paulo: Expressão Popular, 2008. p. 83-105

CEFAI, D. Les cadres de l'action colletive : définitions et problems. In: CEFAI, D.; TROM, D. Les formes de l'action collective : mobilisations dans des arènes publiques. París: École des Hautes Etudes en Sciences Sociales, 2001. p. 51-97

COLETTI, C. A estrutura sindical no campo. Campinas: Editora da Unicamp, 1998.

DELGADO, G. Capital Financeiro e agricultura. São Paulo: Icone, 1985.

Do capital financeiro na agricultura à economia do

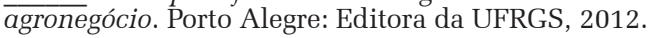

DEL GROSSI, M. Comunicação de pesquisa: delimitando a agricultura familiar nos censos agropecuários brasileiros. Revista Necat, Florianópolis, v. 8, n. 16, p. 40-45, 2019.

GARCIA, A, PALMEIRA, M. Transformação agrária. In: SACHS, I; WILHEIM, J.; PINHEIRO, P. S. Brasil, um século de transformações. São Paulo: Companhia das Letras, 2001. p. 38-77.

GRAZIANO DA SILVA, J. et al. Estrutura agrária e produção de subsistência na agricultura brasileira. São Paulo: Hucitec, 1978.

GRAZIANO DA SILVA, J. F. Progresso técnico e relações de trabalho na agricultura. São Paulo: Hucitec, 1981.

KREIN, J. D. O desmonte dos direitos, as novas configurações do trabalho e o esvaziamento da ação coletiva: consequências da reforma trabalhista. Tempo Social, São Paulo, v. 30, n. 1, p. 77-104, 2018.

LEITE, S. P. et al. Impactos dos assentamentos: um estudo sobre o meio rural brasileiro. São Paulo: Editora da Unesp, 2004

LERRER, D. Revista Agroanalysis: a trajetória da afirmação do "agronegócio" e de consagração de seus agentes. Contemporânea, São Carlos, v. 10, n. 1 p. 273-304, 2020

LERRER, D; MEDEIROS, L. S. Food sovereignty and struggle for land: the experience of the MST in Brazil. In: CONSTANCE, D.; RENARD, M. C.; RIVERA-FERRE, M. (org.). Alternative agrifood movements: patterns of convergence and divergence. Londres: Emerald, 2014. p. 111-135.

MEDEIROS, L. S. Movimentos sociais, disputas políticas e reforma agrária de mercado no Brasil. Rio de Janeiro: Editora da UFRRJ: Unrisd, 2002.

- O sindicalismo rural nas últimas décadas: mudancas e permanências. In: OLIVEIRA, R. V.; BRIDI, M. A.; FERRAZ, M. O sindicalismo na era Lula: paradoxos, perspectivas e olhares. Belo Horizonte: Fino Traço, 2014.

Movimentos sociais, questões fundiárias e mediacões jurídicas: apontamentos sobre as relações entre o Direito e os conflitos sociais. In: LEITE, S. P.; BRUNO, R. (org.). O rural brasileiro na perspectiva do século XXI. Rio de Janeiro: Garamond, 2019. p. 107-127.

MENEZES, M. A. Trabalhadores migrantes: processos de expropriação e reprodução da família. In: MARTINS, R. C. (org.). Ruralidades, trabalho e meio ambiente. São Carlos: EdUFSCAR, 2014. p. 155-174. 
NOVAES, J. R. P.; ALVES, F. (org.). Migrantes: trabalho e trabalhadores no Complexo Agroindustrial Canavieiro (os heróis do agronegócio brasileiro). São Carlos: EdUFscar, 2008.

OFFE, C. Dominação de classe e sistema político: sobre a seletividade das instituições políticas. In: OFFE, C. Problemas estruturais do Estado capitalista. Rio de Janeiro: Tempo Brasileiro, 1984. p. 140-177.

PALMEIRA, M. A diversidade da luta no campo: luta camponesa e diferenciação do campesinato. In: PAIVA, V. (org.) Igreja e questão agrária. São Paulo: Loyola, 1985. p. $43-51$.

Casa e trabalho: nota sobre as relacões sociais na plantation tradicional. In: WELCH, C. et al. Camponeses brasileiros: leituras e interpretações clássicas. São Paulo: Editora da Unesp, 2009. p. 203-215.

PALMEIRA, M.; LEITE, S. Debates econômicos, processos sociais e lutas políticas. In: COSTA, L. F. C.; SANTOS, R. (org.). Política e reforma agrária. Rio de Janeiro: Mauad, 1998. p. 92-165

PICOLOTTO, E. Os atores da construção da categoria agricultura familiar no Brasil. Revista de Economia e Sociologia Rural, Brasília, DF, v. 52, p. 63-84, 2014.

Pluralidade sindical no campo? Agricultores familiares e assalariados rurais em um cenário de disputas. Lua Nova, São Paulo, v. 104, p. 201-238, 2018.

PICOLOTTO, E.; MEDEIROS, L. S. A formação de uma categoria política: os agricultores familiares no Brasil contemporâneo. In: DELGADO, G. C.; BERGAMASCO, S. M. (org.). Agricultura familiar brasileira: desafios e perspectivas de futuro. Brasília, DF: Ministério do Desenvolvimento Agrário, 2017. p. 342-366.

PORTO, J. R. S. O discurso do agronegócio: modernidade, poder e "verdade". Revista Nera, Presidente Prudente, v. 17 , n. 25,2014 . p. 24-46

SCHNEIDER, S.; CAZELLA, A. A.; MATTEI, L. Histórico, caracterização e dinâmica recente do Pronaf - Programa Nacional de Fortalecimento da Agricultura Familiar. In SCHNEIDER, S.; SILVA, M. K.; MARQUES, P. E. M. (org.) Políticas públicas e participação social no Brasil rural. Porto Alegre: Editora da UFRGS, 2004. p. 21-49.
SIGAUD, L. M. A forma acampamento: notas a partir da versão pernambucana. Novos Estudos Cebrap, São Paulo, v. 58, p. $73-92,2000$

As condições de possibilidade das ocupações de terra. Tempo Social, São Paulo, v. 17, n. 1, p. 255-280, 2005.

SIGAUD, L.; ROSA, M. C.; MACEDO, M. Ocupações e acampamentos: estudo comparado sobre a sociogênese das mobilizações por reforma agrária no Brasil (Rio Grande do Sul, Rio de Janeiro e Pernambuco) 1960-2000. Rio de Janeiro: Garamond, 2010.

SILVA, M. A. M. Errantes do novo século. São Paulo: Editora da Unesp, 1999.

'Sabe o que é ficar borrado no eito da cana?'. Estudos Sociedade e Agricultura (UFRRJ), Seropédica, v. 2, p. 359-391, 2013

STOLCKE, V. Cafeicultura: homens, mulheres e capital (1850-1980). São Paulo: Brasiliense, 1986.

TELÓ, F. Dimensões não institucionais da ação política: a relação entre fumicultores e organizações em Santa Cruz do Sul/RS. 2014. Dissertação (Mestrado em Ciências Sociais em Desenvolvimento) - Universidade Federal Rural do Rio de Janeiro, 2014.

THOMAZ JR. A. Reestruturação produtiva do capital no campo no século XXI e os desafios para o trabalho. Pegada, Presidente Prudente, v. 5, n. 1, p. 9-29, 2004.

VERÇOSA, L. V. Os homens-cangurus dos canaviais alagoanos. Um estudo sobre trabalho e saúde. Maceió. Edufal/Fapesp, 2018. 314 p.

VIEIRA, F. B. Articulações internacionais "desde abaixo" em tempos de globalização. In: GOHN, M. G.; BRINGEL, B. Movimentos sociais na era global. Petrópolis: Vozes, 2012. p. $189-210$.

WESZ JR., W. O Pronaf pós-2014: intensificando sua seletividade?. Grifos, Chapecó, v. 30, n. 51, p. 89-113, 2021.

WILKINSON, J. Estado, agroindústria e a pequena produção. São Paulo: Hucitec, 1986. 


\section{ACTORS, CONFLICTS AND PUBLIC POLICIES FOR RURAL AREAS IN CONTEMPORARY BRAZIL}

\author{
Leonilde Servolo de Medeiros
}

The article discusses changes that took place in recent decades on the forms of organization of rural workers in Brazil, emphasizing disputes, convergences and impasses both in the relations between the actors during their constitution process, and with institutional mechanisms and public policies aimed at rural areas. From a brief overview on the changes that affected the rural environment, we discuss the political dynamics of representation regarding family farming, wage labor, and the contemporary dynamics of land disputes. We aim to show how these categories intertwine and how classificatory concerns hide the complex relationship networks that articulates different rural segments and their associations, less and less perceived as hermetic universes. Finally, we examine the growing role of agribusiness and its consequences for rural disputes and for the reconfiguration of the agrarian issue.

KEYwords: Political representation. Family farming. Wage earners. Land conflicts. Agribusiness.

\section{ACTEURS, CONFLITS ET POLITIQUES PUBLIQUES POUR LE MILIEU RURAL AU BRÉSIL CONTEMPORAIN}

Leonilde Servolo de Medeiros

L'article discute les changements qui ont eu lieu au cours des quatre dernières décennies dans les formes d'organisation des travailleurs ruraux au Brésil, mettant l'accent sur les conflits, les convergences et les impasses non seulement dans la relation entre les acteurs eux-mêmes dans leur processus de constitution, mais aussi avec les mécanismes institutionnels et politiques publiques conçu pour le milieu rural. En commençant par un bref historique des changements qui ont affecté le milieu rural, nous aborderons ensuite les dynamiques politique de représentation des catégories agriculture familiale, travail salarié et les formes contemporaines de la dynamique du conflit foncier. On cherche à montrer comment ces catégories s'entrecroise et comment le souci de classification masque le réseau complexe de relations articulant les différents segments ruraux et leurs organisations, de moins en moins perçus comme des univers étanches. Enfin, nous abordons le rôle croissant de l'industrie agroalimentaire et ses implications sur les conflits ruraux et sur la reconfiguration de la question agraire.

Mots-CLÉs: Représentation politique. Agriculture familiale. Salariés. Conflits fonciers. Industrie agroalimentaire.

Leonilde Servolo de Medeiros - Doutora em Ciências Sociais pela Universidade Estadual de Campinas (Unicamp). Professora do Programa de Pós-graduação de Ciências Sociais em Desenvolvimento, Agricultura e Sociedade da Universidade Federal Rural do Rio de Janeiro (CPDA/UFRRJ). Coordenadora do Núcleo de Pesquisa, Documentação e Referência em Movimentos Sociais e Políticas Públicas no Campo, do CPDA/UFRRJ. Bolsista do CNPq. Desenvolve pesquisas na área de movimentos sociais, políticas fundiárias, sindicalismo rural. Publicações recente: Ditadura, conflito e repressão no campo. A resistência camponesa no estado do Rio de Janeiro (org.). Rio de Janeiro: Consequência, 2018, 667 p.; Rural Social Movements in Brazil in the Second Half of the 20th Century: From the Peasant Leagues to the Landless Workers Movement. Oxford Research Encyclopedia of Latin American History. 1ed.Oxford: Oxford University Press, 2020, v. 1, p. 1-25. Pesquisando a contrapelo: a memória dos conflitos e das formas de resistência dos trabalhadores no estado do Rio de Janeiro (1946-1988). In: José Sérgio Leite Lopes; Beatriz Heredia. (Org.). Trabalhadores urbanos, trabalhadores rurais: história e perspectivas. 1 ed. Rio de Janeiro: Editora da UFRJ, 2020, v. 1, p. 161-194; O regime empresarial-militar e a questão agrária no Brasil. In: Jorge Ferreira; Lucília de Almeida Neves Delgado. (Org.). O tempo do regime autoritário. Ditadura militar e redemocratização. Quarta República (1964-1985). O Brasil Republicano v. 4. 9a.ed. Rio de Janeiro: Civilização Brasileira, 2019, v. 4, p. 179-207; Movimentos sociais, questões fundiárias e mediações jurídicas: apontamentos sobre as relações entre o Direito e os conflitos sociais. In: Sérgio Pereira Leite; Regina Bruno. (Org.). O rural brasileiro na perspectiva do século XXI. 1ed. Rio de Janeiro: Garamond, 2019, v. 1, p. 107-127. 